\title{
Comparative Analysis of Patient Outcomes while Receiving Early Palliative Care in Patients with Cancer Using ESAS Score
}

\author{
Nipun Lamba ${ }^{1}$, Ruchika Makkar ${ }^{2}$, Namita Gupta $^{3}$, Sudha Sarna ${ }^{4}$, Seema Khandelwal ${ }^{5}$
}

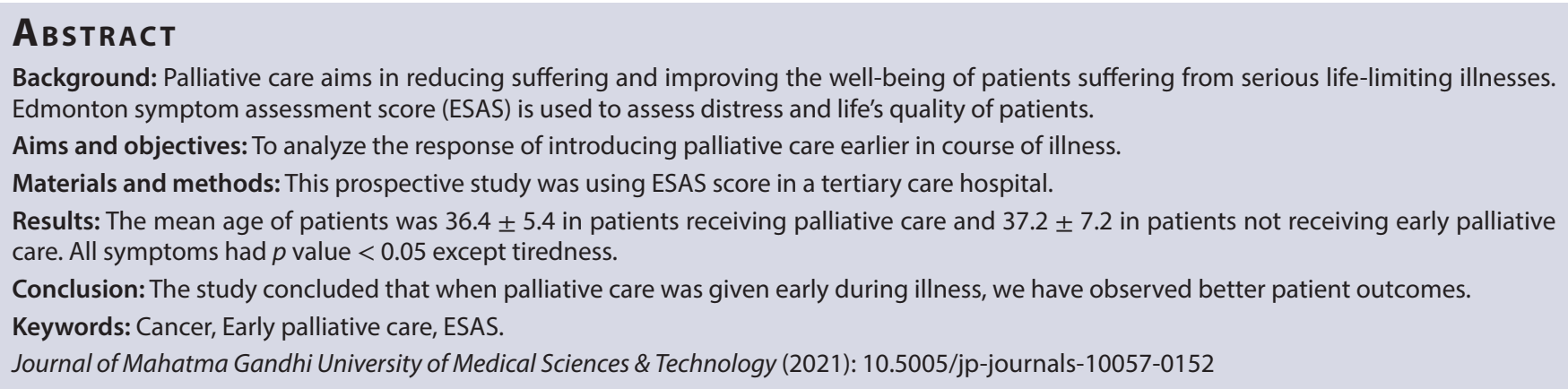

\section{INTRODUCTION}

By providing palliative care, we aim to improve life's quality of patients living with serious life-limiting illnesses. When applied earlier, life's quality has been shown to improve in patients. Patients' concerns are given due regard in palliative care. ${ }^{1}$ WHO and ASCO have recommended early implication palliative care in patients who are suffering from cancer. ${ }^{2,3}$ Dame Cicely Saunders was the main person behind starting palliative care. ${ }^{4} \mathrm{~A}$ study was carried out which states that palliative referrals were made late during illness. ${ }^{5}$ Medical associations state that when introduced earlier, palliative care improves patients' outcomes. ${ }^{6,7}$ The people treating cancer understand that how important is to ensure the early introduction of palliative care and they try to provide it as it improves patients outcome. $^{8,9}$

\section{Materials and Methods}

This study was conducted in the Department of Pain and Palliative Medicine of Mahatma Gandhi Hospital, Jaipur, India. It was a prospective study of 100 diagnosed patients of cancer. In it, 50 patients were allocated randomly into two equal groups.

Due permission was taken from the institutional ethics committee was taken and the Edmonton symptom assessment score (ESAS) was recorded using the ESAS form as a questionnaire (Tables 1 and 2).

The following two groups were compared in this study:

- Group I: Comprised of 50 cases, in which early palliative care was given.

- Group II: Comprised of 50 cases, in which early palliative care was not given.

\section{Inclusion Criteria}

- Patients undergoing cancer treatment.
${ }^{1-5}$ Department of Pain and Palliative Medicine, Mahatma Gandhi Medical College and Hospital, Jaipur, Rajasthan, India

Corresponding Author: Nipun Lamba, Department of Pain and Palliative Medicine, Mahatma Gandhi Medical College and Hospital, Jaipur, Rajasthan, India, Phone: +91 9529725485, e-mail: dr. nipunlamba@yahoo.com

How to cite this article: Lamba N, Makkar R, Gupta N, et al. Comparative Analysis of Patient Outcomes while Receiving Early Palliative Care in Patients with Cancer Using ESAS Score. J Mahatma Gandhi Univ Med Sci Tech 2021;6(1):1-2.

Source of support: Nil

Conflict of interest: None

\section{Exclusion Criteria}

- Patient refusal.

- Patients with altered sensorium or disturbed orientation

Pain score in group I was $2 \pm 1.2$ and group II was $5 \pm 1.7$ which was statistically significant $<0.05$. Tiredness and drowsiness in both were not statistically significant $p>0.05$.

Table 1: Patients' demographics

\begin{tabular}{llll}
\hline & $\begin{array}{l}\text { Patient receiving } \\
\text { early palliative } \\
\text { care }\end{array}$ & $\begin{array}{l}\text { Patient not receiv- } \\
\text { ing early palliative } \\
\text { care }\end{array}$ & p value \\
\hline Age (years) & $36.4 \pm 5.4$ & $37.2 \pm 7.2$ & $>0.05$ \\
Sex male/female & $24 / 26$ & $28 / 22$ & $>0.05$ \\
Weight $(\mathrm{kg})$ & $66.4 \pm 5.2$ & $65.7 \pm 6.3$ & $>0.05$ \\
\hline
\end{tabular}

The mean age in group I was $36.4 \pm 5.4$ and group II was $37.2 \pm 7.2$ years. $p>0.05$ so they were comparable

The mean weight in group I was $66.4 \pm 5.2$ and group II was $65.7 \pm 6.3 \mathrm{~kg}$ $p>0.05$ so they were comparable

(c) The Author(s). 2021 Open Access This article is distributed under the terms of the Creative Commons Attribution 4.0 International License (https:// creativecommons.org/licenses/by-nc/4.0/), which permits unrestricted use, distribution, and non-commercial reproduction in any medium, provided you give appropriate credit to the original author(s) and the source, provide a link to the Creative Commons license, and indicate if changes were made. The Creative Commons Public Domain Dedication waiver (http://creativecommons.org/publicdomain/zero/1.0/) applies to the data made available in this article, unless otherwise stated. 
Table 2: ESAS score

\begin{tabular}{llll}
\hline & $\begin{array}{l}\text { Patient } \\
\text { receiving early } \\
\text { palliative care }\end{array}$ & $\begin{array}{l}\text { Patient not } \\
\text { receiving early } \\
\text { palliative care }\end{array}$ & p value \\
\hline Pain & $2 \pm 1.2$ & $5 \pm 1.7$ & $<0.05$ \\
Tiredness & $3 \pm 2.1$ & $3 \pm 2.2$ & $>0.05$ \\
Drowsiness & $2 \pm 1.9$ & $3 \pm 2.3$ & $>0.05$ \\
Nausea & $2 \pm 1.3$ & $4 \pm 1.7$ & $<0.05$ \\
Appetite & $4 \pm 2.4$ & $6 \pm 2.1$ & $<0.05$ \\
Shortness of breath & $1 \pm 1.3$ & $3 \pm 1.6$ & $<0.05$ \\
Depression & $4 \pm 3.2$ & $5 \pm 2.1$ & $<0.05$ \\
Anxiety & $3 \pm 2.5$ & $6 \pm 0.1 .3$ & $<0.05$ \\
Well-being & $8 \pm 2.1$ & $4 \pm 1.8$ & $<0.05$ \\
\hline
\end{tabular}

There was a decreased incidence of nausea and shortness of breath appetite as well as depression and anxiety in the group that received early palliative care $p<0.05$.

There was increased feeling of well-being in patients receiving palliative care group I $8 \pm 2.1$ vs group || $4 \pm 1.8$ as compared to not receiving palliative care $<0.05$.

\section{Discussion}

ESAS stands for Edmonton symptom assessment score. It is a standard document that is used to assess the severity of symptoms in cancer patients. Early palliative care enables patients to have a better quality of life. Palliative care provides multiple layers of support to the patient in terms of pain management, symptom management, a better understanding of disease and associated symptoms, and moral and psychological support. ${ }^{10-13}$ Palliative care should be integrated into oncology practice early in during illness ${ }^{3}$ Referrals to palliative care often come too late to improve QOL for patients with cancer. It is usually seen that palliative care referrals are made later in the disease trajectory. ${ }^{5}$ Palliative has been shown to improve the quality of life of patients. It should be stated as early as a diagnosis is made. It enables patients and caregivers to have reduced psychosocial distress and improved outcomes.

\section{Conclusion}

Early palliative care enables patients to have better management of their pain and other associated symptoms. Patients who receive palliative care earlier in their illness have better outcomes as well as it also enables families and caregivers to have reduced levels of anxiety and better quality of life.

\section{References}

1. Higginson I, Evans C. What is the evidence that palliative care teams improve outcomes for cancer patients and their families? Cancer J 2010;16(5):423-435. DOI: 10.1097/PPO.0b013e3181f684e5.

2. WHO. WHO Definition of Palliative Care; 2013. Available from: http:// www.who.int/cancer/palliative/definition/en/.

3. Smith TJ, Temin S, Alesi ER, et al. American Society of Clinical Oncology provisional clinical opinion: the integration of palliative care into standard oncology care. J Clin Oncol 2012;30(8):880-887. DOI: 10.1200/JCO.2011.38.5161.

4. Palliative care Brochure National Institute of Nursing Research. U.S. Department of Health and Human services. National Institute of Health. Available from: http://www.ninr.nin.gov.

5. Bruera E, Hui D. Integrating supportive and palliative care in the trajectory of cancer: establishing goals and models of care. J Clin Oncol 2010;28(25):4013-4017. DOI: 10.1200/JCO.2010.29.5618.

6. Smith TJ, Dow LA, Virago E. Giving honest information to patients with advanced cancer maintains hope. Oncology (Williston Park) 2010;24(6):521-525.

7. Peppercorn JM, Smith TJ, Helft PR. American Society of Clinical Oncology statement: toward individualized care for patients with advanced cancer. J Clin Oncol 2011;29(6):755-760. DOI: 10.1200/ JCO.2010.33.1744.

8. Fisch MJ, Lee JW, Weiss M. Prospective, observational study of pain and analgesic prescribing in medical oncology outpatients with breast, colorectal, lung, or prostate cancer. J Clin Oncol 2012;30(16):1980-1988. DOI: 10.1200/JCO.2011.39.2381.

9. Hui $\mathrm{D}$, Mori M, Parsons HA, et al. The lack of standard definitions in the supportive and palliative oncology literature. J Pain Symptom Manage 2012;43(3):582-592. DOI: 10.1016/j.jpainsymman.2011.04.016.

10. Elsayem A, Swint K, Fisch MJ, et al. Palliative care inpatient service in a comprehensive cancer center: clinical and financial outcomes. J Clin Oncol 2004;22(10):2008-2014. DOI: 10.1200/JCO.2004.11.003.

11. Jack B, Hillier V, Williams A, et al. Hospital based palliative care teams improve the insight of cancer patients into their disease. Palliat Med 2004;18(1):46-52. DOI: 10.1191/0268216304pm846oa.

12. Jack B, Hillier V, Williams A, et al. Hospital based palliative care teams improve the symptoms of cancer patients. Palliat Med 2003;17(6):498502. DOI: 10.1191/0269216303pm794oa.

13. Manfredi PL, Morrison RS, Morris J, et al. Palliative care consultations: how do they impact the care of hospitalized patients? J Pain Symptom Manage 2000;20(3):166-173. DOI: 10.1016/s0885-3924(00)00163-9. 